\title{
Drawing with Robots: An Experience Report (Fundamental)
}

\section{Olivia Mambo Nche-Eyabi, Clemson University}

Olivia Mambo Nche-Eyabi is currently a Ph.D. student in Human Centered Computing. Her focus is Robotics and she investigates innovative ways of using robots to facilitate engineering education. She graduated from Anderson University in 2010 with a Bachelor's Degree in Business Administration and Computer Information Systems and from Northwestern University in 2012 with a Master's Degree in Computer Information Systems.

\section{Barbara Jeanne Ramirez, Clemson University}

Barbara Ramirez has been a faculty member at Clemson University for more than 30 years. Her primary teaching areas have included technical writing as well as other professional writing courses and English as a Second Language. In addition, she has served as a writing consultant for various engineering departments at Clemson. She earned her BA in Secondary Education- English and her MA in Literature from Clemson University.

\section{Sekou Remy, Clemson University}

Sekou L. Remy is a researcher focused on removing barriers to effective use of Robotics and Cloud Computing in our homes, schools, and training centers. Dr. Remy is currently an Assistant Professor in Human-Centered Computing, and comes to Clemson from the University of Notre Dame, where he was a Moreau Postdoctoral Fellow. He has also been a part-time instructor in Computer Science at Spelman College. A graduate of the Georgia Institute of Technology (ECE) and Morehouse College (CS), Remy leverages education in both engineering and liberal arts to enable change. 


\title{
Drawing with Robots: An Experience Report (Fundamental)
}

\begin{abstract}
Drawing with Robots is an activity that incorporates robots as a mechanism to facilitate tangible applications of basic art. This activity, which was conceived as an extension of the Hour of Code movement, seeks to reinforce the transition of abstract concepts to something more concrete. At the end of this "Second Hour of Code," students will have created a tangible artifact, which represents the knowledge acquired during the activity. Students were supported through a four-stage process as they 1) conceived of the task they would like a robot to perform, 2) developed the steps needed for the task to be performed, 3) decided how to implement the required steps, and 4) assessed whether the intended aims were achieved. At each stage of the process, the students were assisted in re-evaluating their goals. In this paper, we present a report of our participation in two Drawing with Robots events. This experience report summarizes the design of the activity, the lessons learned in its execution and a description of the engineering skills taught during these sessions. We found that the majority of the students who participated in our activities were able to learn such engineering skills as creativity, math, problem solving, programming, assessment and analytic skills as evidenced in the final artifacts that they created. We also share the observations from working with students and offer recommendations for others considering similar activities
\end{abstract}

\section{Introduction}

Drawing with Robots is an activity that extends the Hour of Code, a campaign to encourage 10 million students of all ages to try computer science for one hour. Most of the current activities result in the creation of computer programs and other deliverables that are digital and, thus, exist only on the computer [11]. In Drawing with Robots, our aim is to extend the Hour of Code to create tangible evidence of the student's effort. By using computing and mathematics to create art, we see an opportunity to engage a larger audience and also to incorporate a discussion of other aspects of STEM education.

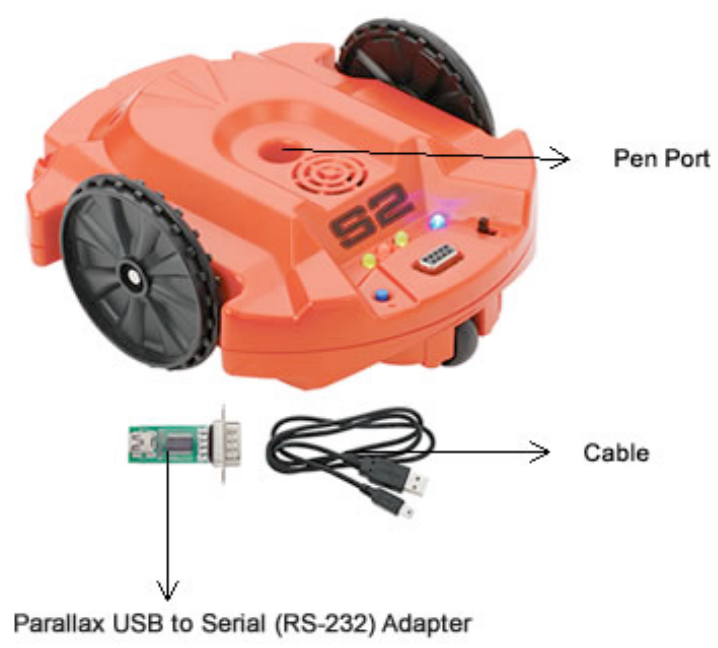

Figure 1. Scribbler 2 robot 
In this experience report we present the activity, describe the resources used, and share some of the insights acquired during implementation.

In 2015, this project was realized under the title "R2D2 meets Rembrandt," and utilized the Parallax's Scribbler S2 robot shown in Figure 1 and its associated Graphical User Interface (GUI) shown in Figure 2. This robot has the ability to draw various shapes, letters, numbers and pictures as it moves, facilitated by the pen port that can hold a Sharpie or any similar marker. The S2 can be programmed by changing the Propeller source code in the S2 BASIC-like Spin language to accomplish the challenges of a specific activity or by using the GUI tile-based programming tool. The latter is a practical tool for introducing K-12 students to robotics in particular and programming in general [7].

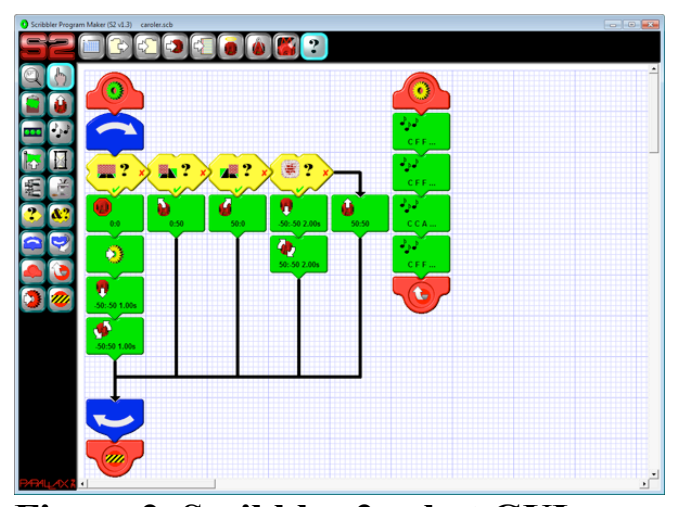

Figure 2. Scribbler 2 robot GUI

The S2 robot was very relevant to our activities because it has been observed, that robotics can be an effective stimulus for catalyzing student interest in STEM disciplines $[1,3,4]$. This finding motivated the Drawing with Robots activities, which sought as their goal to reinforce the transition from abstract concepts to concrete objects. Specifically, student participants leveraged robots as a mechanism to facilitate tangible applications of basic mathematics and computing to create art. Furthermore, robots typically enable proactive learning and, therefore, suggest an engaging way to address several challenging concepts that typically discourage students in STEM-related courses. For example, teaching with the aid of robots allows students to experience basic physics when trying to determine the correct gear wheel ratio to keep the robot from losing its balance. Programming a robot to navigate through a maze, another example, provides students the opportunity to understand coordinates on a plane, and they can learn about frequencies in an exciting way by using a radio controller to control the robot [1]. While not exhaustive, these examples illustrate how robotics can help students learn STEM concepts. Using robots as a learning tool also provides an innovative way of incorporating technology into the learning process. This is important because the role of technology in our society continues to evolve. Robots can help to inspire greater enthusiasm in students while exposing them to important concepts in new ways [8]. 
Prior works also show that the use of Educational Robotics can enrich learning as the process of building or programming a robot affords the students the opportunity to understand key concepts and ideas from science and engineering [3, 10]. For example, Chin et al. [2] reported their findings concerning the development and testing of an educational robot-based learning system. In their research, they combined multimedia objects with an educational robot to create an application consisting of an editing tool and a server to transform the study material. Their primary objective was to assess the impact of this application on the performance and the level of motivation of elementary students. They used a four-stage experimental procedure involving a pre-test, a post-test, a set of learning activities, and a survey questionnaire to assess the effectiveness of their system. The participants were assigned to either the proposed learning system or a PowerPointbased learning system (control group). Based on their results, the students who used the robot-based learning system demonstrated more improvement in their performance than those in the control group. To measure the motivational factors of attention, relevance, confidence, and satisfaction, they used a questionnaire based on the Instructional Materials Motivation Survey, the results indicating that the students recorded high scores in satisfaction and relevance motivational factors. These researchers concluded that the overall learning interest, motivation and performance of students could be improved by including robot-based learning systems in the educational process [2].

In a similar publication, Curto and Moreno [3] presented a set of practical proposals for using robots in an educational environment. They based their work on the assertion that the introduction of a robot in the classroom, both at school and in extracurricular activities, could hone such engineering skills as creativity, problem solving, and teamwork. They also postulated that in the future, robots would play an even greater role in the educational process. As these two studies suggest, robots have unique characteristics, which make them suitable to be used as educational tools. This further explains why the S2 was significant for our exercises. Our Drawing with Robots' experiences supported these assertions as they indicated that students were able to learn basic engineering skills through our robotic activities.

\section{Co-curricular setting}

Our experiences are rooted in the execution of the activity in a co-curricular setting at an exhibit at Artisphere2015 and at a Fall Festival, both in Greenville, South Carolina. A co-curricular setting complements what students learn in school with respect to STEM subjects. This strategy was selected since it has been shown that informal learning settings, i.e. those outside the framework of schooling, offer the potential to stimulate interest, initiative, experimentation, discovery, play, imagination, and innovation in middle school students $[5,6]$. This is beneficial for the students considering that past research [3] on K-12 engineering indicates that students often lack interest in STEM education, an issue for tomorrow's workforce since engineering and technology drive innovation and provide an economic competitive edge. We also think that this setting added value to our activities because it is a supportive low stress entry point, with low failure rates. All of these are important ingredients to improve students' confidence levels. This report, which covers the time period March--October 2015, includes 
observations, experiences and lessons learned from these two outreach events incorporating the activities of our project.

\section{The Events}

Our first Drawing with Robots event took place in April 2015 at Artisphere and the second in October 2015 at the Fall Festival of the Summit Drive Elementary School, both in Greenville, South Carolina. Our team partnered with the STEAM (Science Technology Engineering Art and Math) Network's outreach effort for both activities. Prior to our two events, we acquired four S2 Scribbler robots, then spent three weeks completing preliminary steps crucial to the success of this program. First, we installed all the required software. Since the S2 can be programmed using its own graphical user interface, we installed this software onto the computers we planned to use. The link to this software was obtained from the vendor's website. We chose the GUI because research [10] has shown that it is easier to use than its text-based counterpart.

Our most important step was to conceive design ideas for our art catalogue. An initial brainstorming session was used to formulate possible projects and determine the workflow for the activities. After each activity was conceived, we figured out the steps required to accomplish its goal. We also studied the tutorials in order to understand how to manipulate the S2 robot. Then, we proceeded to program the S2 and subsequently tested the code to ensure that there were no errors, debugging the program as necessary. As we progressed, we documented the various algorithms, other relevant data and updated our catalogue. The shapes in our catalogue included a square, a star, a triangle, an octagon, and additional designs created by combining these shapes in various ways. A good example of such a design is the tunnel (Figure 3), which we created by combining a set of three octagons and looping through our code eight times.

The steps involved in creating a simple shape like a square are as follows:

1) Drag and drop a loop icon onto the canvas between the start and end blocks

2) Set the loop counter to four

3) Drag and drop a motion block onto the canvas inside the loop

4) Click on the motion block to open the edit menu

5) Ensure that the wheels of the $S 2$ robot icon are set to move forward

6) Adjust the time as desired depending on the dimensions of the square

7) Click the check mark

8) Repeat steps 3 and 4, adjusting the wheels to go in opposite directions to ensure a turn

9) Set the time to two seconds to ensure that the turn angle is ninety degrees

10) Click the check mark

11) Connect the S2 to the computer using the cable and the USB to Serial Adapter

12) Click on the download button at the top of the GUI to download the program to the robot.

13) Disconnect the cable, put a marker in the pen port, place the robot on a piece of paper, turn it on and let it draw 


\section{Artisphere - April 2015}

Artisphere, an annual three-day event held in Greenville, gives people who love art the opportunity to meet exhibiting artists and buy original works of art [4]. The STEAM Network participated in this event in April 2015. Our workstation in the Network's tent included a large sand box covered with plotting paper on which the students drew the shapes they programmed using the S2. Two 6' tables in the back housed the laptops used to teach the students how to program the robot and all the other accessories like different color Sharpies and batteries. After the students finished programming, their code was loaded onto the robot, and we moved to the sandbox where the S2 drew the design.

As the participants approached our workstation, we offered to teach them how to program the S2 to draw any shape of their choice using the S2 GUI. While some suggested a shape, some were not sure about what they wanted. In these situations, we proposed a picture from our catalogue to them. Once we settled on a project, we spent time with them, brainstorming to decide how best to tackle the design problem, a process that encouraged algorithmic, analytical, critical and computational thinking. Next, we taught the students how to code their conceived design on the S2 GUI. We then showed the students how to download the program onto the robot; at this point they moved to the sand box where the S2 drew their pictures, which the students colored if they chose to do so.

The students expressed a general sense of accomplishment when they saw the robot draw the design that they had conceived and programmed on the S2. Sometimes they came back for a repeat experience or to extend their project to include something more complicated. However, when there were unexpected outcomes in the pictures indicating errors in the code, we helped them find the errors and fixed their code until it produced the desired results. Students from different age groups with various programming experiences came to this event, both those who sat down and knew what to do and others who were experiencing coding for the first time

\section{Fall Festival - October 2015}

The Summit Drive Elementary School experience was logistically different from Artisphere, with fewer participants but with the same outcome. Here we used two low tables designed for elementary school students rather than the sand box, creating a work area surrounded by chairs for each. In addition, each work area had a laptop, a robot, markers of various colors and drawing paper. We lined the tables with plastic before placing the drawing papers on them to prevent the markers from bleeding onto the tables. The remaining two robots were on standby, set up and ready to go if needed.

The low tables rendered everything completely accessible to the students irrespective of their heights. They were circular and large, providing enough room for both the computer and the robot. We sat with the students, teaching them how to program on the computer, download the program onto the robot and let it draw the shape without moving from these tables. Two workstations meant that we were able to assist multiple students at the same time, thus reducing the wait time for those anxious to try the other activities at the 
Fall Festival. As a result, sometimes we had up to ten students between our two tables to work with at once, and at other times we had only one or two.

The parents displayed an interest in the Drawing with Robots activity, asking questions related to how they could obtain the S2 and the frequency of these events. Some teachers were also very interested because they recognized the impact of the activity on the students with respect to engineering skills

\section{Discussion}

The main purpose of these activities was to reinforce vital engineering skills, which potentially impact the future success of students who choose to go into this field. Some of the skills that we focused on included creativity, math, problem solving, programming, assessment and analytic skills. Creativity, a core element of engineering education, is the driving force behind innovation, and we sought to encourage this skill by engaging the students in the process of creating art using robots. This afforded the students the opportunity to conceive, create and implement a design. During our activities, the students were encouraged to immerse themselves in a thinking process, to imagine and to conceive a design because design creation originates from inspiration to formalized reasoning, with the resulting artifacts being typical representations that express characteristics of the objects themselves. They are also products of the imagination of the designer. Occasionally, they can be conceived as a remix of a previous design since artifacts have the potential to inspire, guide, and facilitate the creation new designs [10].

The designs that the students conceived were later transformed into art by programming them onto the S2 robot. We observed that about two thirds of the participants actively engaged in this creativity phase and were able to conceive of challenging yet beautiful designs. One example was the case of a young lady who wanted to program the S2 to draw a castle. This design was a new and exciting challenge because a castle was not in our catalogue of shapes, meaning that we did not have predetermined steps for creating it. Together with this young lady, we went through the process of brainstorming, programming, testing and debugging our code until we created the castle design that she had conceived. The remaining third of the students could not conceive their own original ideas, meaning that they reproduced something from our catalogue or remixed two of our designs to create an entirely new one. These activities thus encouraged the students to be creative and discover fascinating concepts in the process of creating art.

In addition, this "Second Hour of Code" also reinforced math skills. At both of our events, the students referred to geometry for inspiration to create art, finding that simple shapes like squares, rectangles, circles, and octagons could become the foundation for creating previously inconceivable and sometimes complicated designs. A good example was the realization that twelve hexagons separated by an angle of approximately 45 degrees created the circular image seen in Figure 3. In essence, a circular pattern emerged from a collection of non-circles, showing students how a linear figure could be transformed into a circular one. 


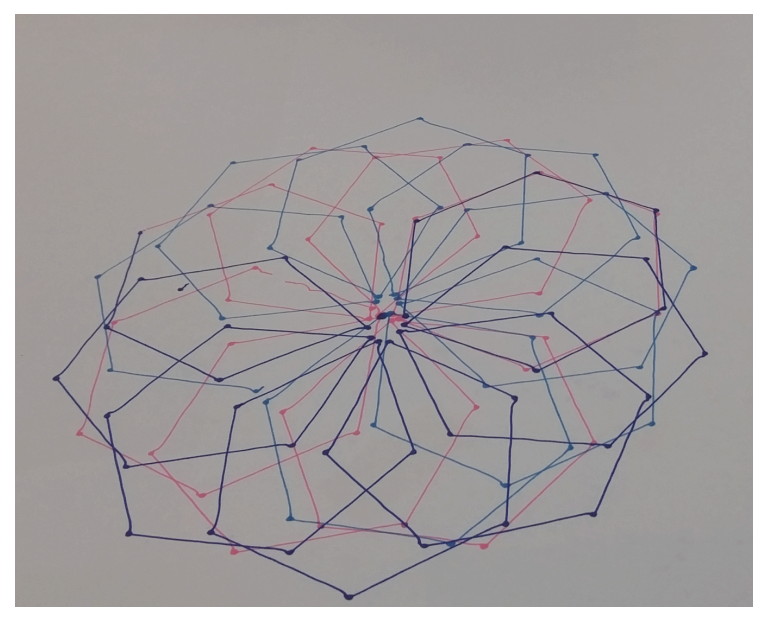

\section{Figure 3. S2 picture of multiple hexagons}

Students also found that twenty-seven octagons arranged in sets of threes and separated by an angle of approximately ten degrees produced a tunnel. An example of this tunnel can be seen in Figure 4 below.

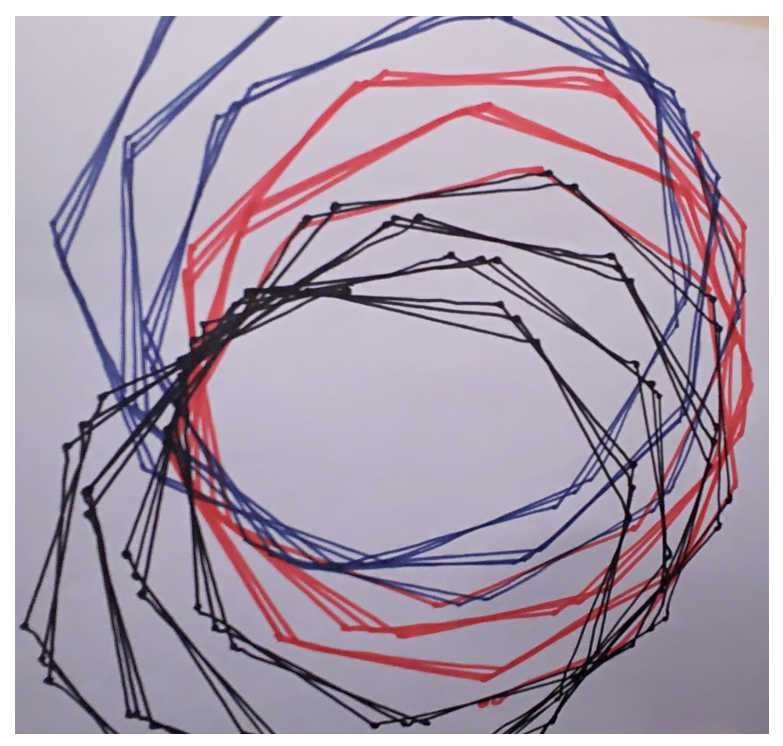

\section{Figure 4. S2 Tunnel}

The early design phase of brainstorming [10] called for a review of geometry and as such facilitated the re-enforcement of math concepts. For example, in the process of designing a piece of art consisting of squares, students had to review the unique characteristics of a square: the fact that it has four equal sides separated by four right angles. This reenforcement of basic math concepts was necessary to ensure that the design exhibited the characteristics of the artifact that inspired it.

These activities also introduced the participants to rudimentary programming concepts like algorithms and loops while fostering problem solving and analytic thinking skills, all 
crucial to engineering. The students were intrigued to discover that in order to program the S2 to draw something as simple as a square, they had to think through the process and carefully note every step to obtain the expected outcome. This attention to detail is typical of programming, and, therefore, it is good for the students to experience this thought process early in their education. During the events, the students had to go through the "test and debug" process for their code several times before they could accomplish the task of programming the S2 to draw the picture expected. We found that this process helped them to develop the engineering skill of assessment because they had to test the code to assess their progress and evaluate the degree to which their current art resembled the envisioned design. It also allowed the students to discover for themselves a pathway for addressing project challenges and pitfalls while trying to solve a problem. This aspect, coupled with the process of finding candidate solutions for the problem of creating the conceived design, helped the students hone their problem solving skills.

Based on our observations, we could tell that the students were motivated to learn programming. This was evident by the fact that they were anxious to see the robot do something, a desire that motivated them to try the activities. When they completed their artifacts, they expressed a sense of satisfaction and a feeling of accomplishment for having created art by programming the $\mathrm{S} 2$ the robot. This confirms the findings of Chin et al. [2] who concluded that the overall learning interest, motivation and performance of students could be improved by including robot-based learning systems in the educational process. We imagine that this satisfaction will help improve their confidence levels, and encourage them to explore more deeply the field of engineering.

One of the practical proposals presented by Curto and Moreno [3] for an educational environment with educational robots is their design of educational projects.

The goal of this type of project is to change students' misperception of engineering and technology. Such activities are designed in a game or other creative framework requiring teamwork and collaborative learning. Designing educational projects in this way facilitates the integration of technology in education by focusing on design and engineering exercises, which help students develop a positive attitude towards engineering and technology by mitigating their prejudices and misconceptions. Our activities are conveniently nested within this category as they focus on design and engineering exercises to enhance students' perception of this field through the process of creating final artifacts using robots.

Finally, hands-on learning experiences have been shown to help students discover for themselves the means for solving project challenges [5]. The Drawing with Robots activities explored this finding, with our experience supporting the fact that proactive learning can help students discover techniques of solving problems for themselves.

\section{Conclusion}

Drawing with Robots was designed to extend the Hour of Code by using robots to create tangible evidence of students' efforts and to hone crucial engineering skills like creativity, math, problem solving, programming, assessment and analytic skills in the 
process. This "Second Hour of Code" spanned two outreach initiatives, and at their end, we observed that students of all ages and grades interacted easily with the S2 robot and did not take too long to learn how to program it. On average, it took the younger students $\left(4^{\text {th }}-6^{\text {th }}\right.$ grade) about fifteen minutes to learn how to program the S2 to draw a simple shape like a square, and this age group needed significant intervention from us. We had to explain the process to them and walk them through at least one example before they could work independently. The older students $\left(7^{\text {th }}-12^{\text {th }}\right.$ grade) took less than ten minutes to do the same activity, with most needing little intervention. Typically, it was sufficient to explain the process once for them to start working independently. However, during their first attempt, they needed some level of guidance to become acquainted with the system. This was different from the younger students who actually had to see us do an example before they could make their first attempt. Occasionally, we had some students who did not need any initial intervention because they liked to figure things out for themselves or they already had some exposure to GUI programming.

The number of students who came to our work area determined how many we worked with at the same time. Sometimes we were able to work one-on-one with the students, and at other times we had to work with a group of up to five at once. Even in this case, the students took turns programming the S2 and drawing their own designs independently. The majority of the students completed their designs and were impressed with their creation; some returned for a repeat experience. It is worth noting that there were a few students who quit because they were not patient enough to go through the debugging process when they were having trouble programming their designs.

Parents and teachers who came to our events were impressed with the results of these activities and asked us questions about how to acquire the S2. The teachers in particular noted that Drawing with Robots is a good enrichment activity for K-12 students. We also observed that many female students were drawn to our activities and were eager to conceive a design and program the $\mathrm{S} 2$ to draw it. They were also successful in accomplishing their goals. This led us to conclude that the $\mathrm{S} 2$ can be a very useful and easy-to-use tool in the classroom and co-curricular settings to introduce programming to students of different ages and genders.

Most of the students were excited and eager to program the robot to draw a design, confirming that robots are exciting fun tools that can help students learn difficult concepts like programming. Because students learned to program easily using the S2 GUI, we conclude that this programming tool can help introduce students to fundamental concepts in programming in a relatively stress-free way.

Our outreach activities also enabled the students to go through a process of conceiving a task they would like a robot to perform, developing the steps needed for the task to be completed, deciding how to implement the required steps and debugging the code when necessary. This served to introduce the students to the software development life cycle as well as to foster basic math, problem solving, creativity, programming, assessment and analytic skills. Those students who had never been exposed to programming nor had interacted with a robot had the opportunity to do so. Furthermore, all the students we 
worked with had to review basic geometry concepts, and many of them were able to conceive new project designs. The majority of them ended up creating final artifacts, which were tangible pieces of evidence of their efforts in applying the skills that they had learned during our activities. This led us to conclude that Drawing with Robots can be very instrumental in teaching and honing important engineering skills either in a classroom or in a co-curricular environment.

\section{References}

[1] Eubanks, A. M., Strader, R. G., \& Dunn, D. L. (2011). A comparison of compact robotics platforms for model teaching. Journal of Computing Sciences in Colleges, 26(4), 35-40.

[2] Chin, K. Y., Hong, Z. W., \& Chen, Y. L. (2014). Impact of using an educational robot-based learning system on students' motivation in elementary education. Learning Technologies, IEEE Transactions on, 7(4), 333-345.

[3] Curto, B., \& Moreno, V. (2013). A robot in the classroom. In Proceedings of the First International Conference on Technological Ecosystem for Enhancing Multiculturality (pp. 295-296). ACM.

[4] De Cristoforis, P., Pedre, S., Nitsche, M., Fischer, T., Pessacg, F., \& Di Pietro, C. (2013). A Behaviorbased approach for educational robotics activities. Education, IEEE Transactions on, 56(1), 61-66.

[5] Ganesh, T. G. (2011). Design-based research: A framework for designing novel teaching and learning experiences in middle school engineering education. In IEEE Frontiers in Education Conference (FIE), (pp. T2F-1).

[6] Schweingruber, H. A., Duschl, R. A., \& Shouse, A. W. (Eds.). (2007). Taking Science to School: Learning and Teaching Science in Grades K-8. National Academies Press.

[7] Parallax Inc. Scribbler 2 Robot. 2016 https://www.parallax.com/product/28136

[8] Connaughton, R., \& Modlin, M. (2009). A modular and extendable robotics platform for education. In IEEE Frontiers in Education Conference (FIE). (pp. 1-4).

[9] South Carolina department of parks and recreation. 2015. http://discoversouthcarolina.com/products/26504

Wahid, S., Branham, S. M., McCrickard, D. S., \& Harrison, S. (2010, August). Investigating the relationship between imagery and rationale in design. In Proceedings of the 8th ACM Conference on Designing Interactive Systems (pp. 75-84).

[10] Wientrop, D and Wilenski, U. 2015. To Block or not to Block, That is the Question: Students' Perceptions of Blocks-based Programming ACM IDC 2015.

[11] Wilson, C. (2015). Hour of code---a record year for computer science. ACM Inroads, 6(1), 22-22. 